\title{
Vertragsärzte wollen Streikrecht
}

Was an Kliniken erlaubt ist, soll niedergelassenen Ärzte nicht verboten sein: Fast alle Vertragsärzte plädieren laut einer Umfrage für das Streikrecht. Das will Medi jetzt juristisch prüfen lassen.

Vertragsärzte wünschen sich nach einer Umfrage des Medi-Verbunds ganz überwiegend das Streikrecht.

Medi hat in einer Fax-Umfrage rund 43.000 Vertragsärzte in Baden-Württemberg, Bayern, Hessen und RheinlandPfalz angeschrieben, 6609 haben geantwortet. Knapp 96\% (6343) sprechen sich für das Streikrecht aus, 125 Ärzte sind dagegen. Gefragt wurde zudem, ob Vertragsärzte eine bundesweite Befragung zu diesem Thema befürworten. Hier votierten 6398 Teilnehmer mit Ja, 86 lehnen dies ab.

\section{Baden-Württemberg liegt vorn}

Am stärksten war der Umfrage-Rücklauf in Baden-Württemberg, wo sich 3054 von
13546 angeschriebenen Ärzten beteiligt haben (22,5\%). Der Medi-Vorsitzende Dr. Werner Baumgärtner wertet das Votum seiner Kollegen als „eindeutig“.

\section{Juristische Prüfung steht aus}

Man werde das Thema weiterverfolgen und juristisch prüfen lassen. Medi fordert das Streikrecht für Vertragsärzte, weil der Kollektivvertrag durch Kliniköffnungen, Selektiv- und IV-Verträge ausgehöhlt worden sei.

(fs)

www.aerztezeitung.de

\section{Bewertung im Netz: Gericht setzt Grenzen}

\section{Ärzte müssen Kritik von Patienten im Netz nicht immer klaglos hinnehmen. Im Fall eines Zahnarztes haben Richter jetzt einem Portalbetreiber deutliche Auflagen gemacht.}

Im Streit um Bewertungsportale im Internet hat das Landgericht Nürnberg-Fürth einem Zahnarzt vorläufig Recht gegeben.

Weil dieser einer Kritik substanziiert widersprochen habe, hätte der Portalbetreiber die Angelegenheit genauer prüfen müssen, entschied das Landgericht in einem Eilbeschluss.

Danach muss der Betreiber die anonymen Vorwürfe bis auf Weiteres aus dem
Netz nehmen. Der Nutzer der Plattform hatte behauptet, der Zahnarzt sei inkompetent. Ungeachtet medizinischer Standards gehe es ihm vorrangig um seine wirtschaftlichen Interessen.

\section{Erfolgte die Behandlung tatsächlich?} Gegenüber dem Betreiber der Plattform konterte der Zahnarzt, in dem von dem Kritiker angegebenen Zeitraum habe er

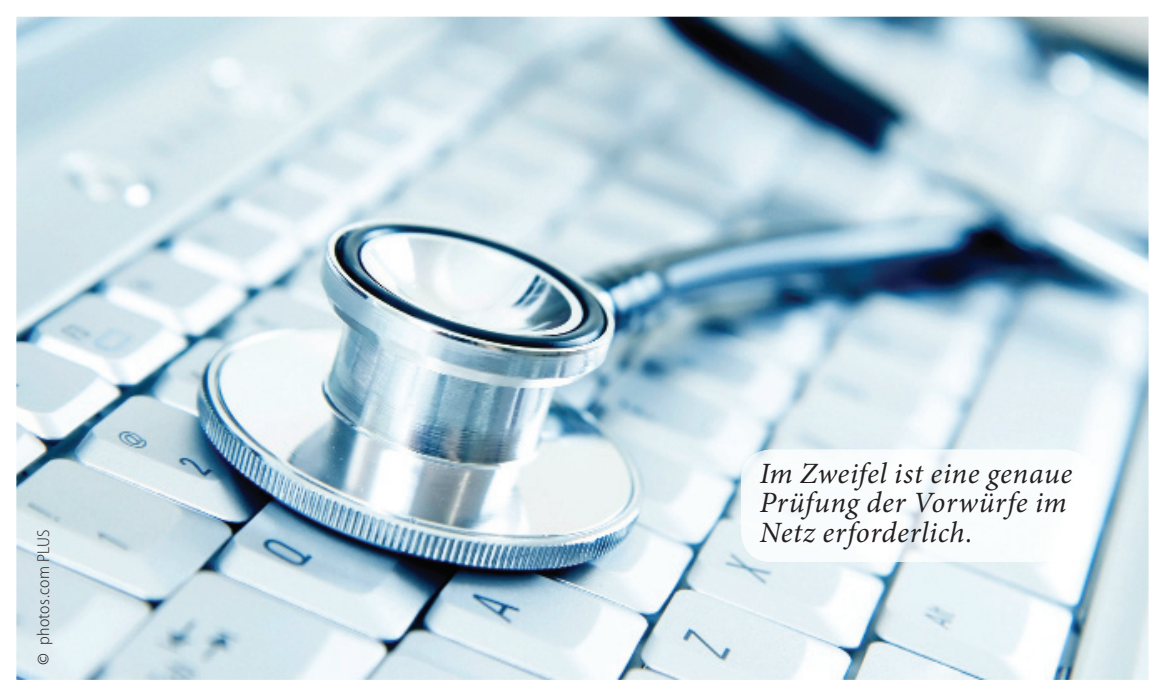

überhaupt keine Implantatbehandlung durchgeführt. Schon von daher müsse die Kritik falsch sein.

Auf Nachfrage des Plattformbetreibers bestätigte der Nutzer jedoch seine Angaben. Unter Hinweis auf eine „Pattsituation" beließ der Betreiber die Vorwürfe daher im Netz.

Auf die sehr konkrete Beanstandung des Zahnarztes hin hätte der Plattformbetreiber die Vorwürfe aber genauer prüfen müssen, entschied nun das Landgericht Nürnberg. Zumindest hätte er Belege verlangen müssen, dass die Behandlung tatsächlich stattgefunden hat.

\section{Grundsätzlich gilt: Kritik im Netz ist erlaubt}

Weil dies nicht geschehen sei, müsse der Betreiber die Vorwürfe löschen, bis die Sache abschließend geklärt ist. Eine solche Klärung könnte im konkreten Streitfall das nun anstehende Hauptverfahren bringen.

Grundsätzlich müssen aber auch Ärzte und Zahnärzte Kritik und Bewertungen im Internet hinnehmen. Nach einem Urteil des Oberlandesgerichts (OLG) Frankfurt am Main (Az.: 16 U 125/11) gilt dies auch für anonyme Bewertungen.

www.aerztezeitung.de 